\title{
Examination of Mechanical Behavior of E-Glass Fabric Reinforced Polyester Composites
}

\author{
Praveen. R, P.Kumaran, Akash , Divyakrishna, Kavin kumar
}

\begin{abstract}
Cooling system this study aims at fabrication Glass Fiber Reinforced Polyester (G-P) Composites and investigation of their Physico-Mechanical Properties. In the present work Polyester based composites were fabricated manually by compression. Mechanical Properties are evaluated according to American Society for Testing and Materials (ASTM) D-638 and D-790 respectively. Further, Surface Morphology is emphasized to study their microstructure under varying magnifications.
\end{abstract}

Key words: Glass fibre, Reinforcement, Metal matrix, composite

\section{INTRODUCTION}

In the present era of modern engineering Fiber Reinforced Polymers [FRP] are broadly used in automobile, aerospace, aircraft, space vehicle, off-shore structure, marine, sporting goods and electronic appliances [1] .It mainly consists of Polymer as a matrix and fibers as a primary reinforcing material having a distinct interface between them. The Fibers are of high strength and modulus mainly intended to bear the load which has being transformed by matrix [2].

A matrix not only transfers the load, but also guards the fiber from the vulnerable environment damage before, during and after composite processing. Composite is a combination of one or more materials either in fibers, sheets, or particles, and it is set in layer by layer to form a matrix phase.

The composites fiber or particle are comparatively stiff and strong compared to reinforced material acts as a principal load carrying member. The matrix transfers the loads between medium. The matrix is more ductile than the fibers

Revised Manuscript Received on December 30, 2019.

* Correspondence Author

R.Praveen, Department of Mechanical Engineering, Aarupadai Veedu Institute of Technology, Vinayaka Mission Research Foundation India. Email: praveen@avit.ac.in

P.Kumaran,, Department of Mechanical Engineering,Aarupadai Veedu Institute of Technology, Vinayaka Mission's Research Foundation, kumaranp@avit.ac.in

Akash - UG Scholar, Department of Mechanical Engineering,Aarupadai Veedu Institute of Technology, Vinayaka Mission Research Foundation India.

Divya Krishna -UG Scholar, Department of Mechanical Engineering,Aarupadai Veedu Institute of Technology, Vinayaka Mission Research Foundation India.

Kavin kumar - UG Scholar, Department of Mechanical Engineering,Aarupadai Veedu Institute of Technology, Vinayaka Mission Research Foundation India.

(C) The Authors. Published by Blue Eyes Intelligence Engineering and Sciences Publication (BEIESP). This is an open access article under the CC BY-NC-ND license (http://creativecommons.org/licenses/by-nc-nd/4.0/) and helps for composite toughness. The matrix protects the fiber from external and environmental damage.

Fiber Reinforcement Polymer Composites

FRP composites are used due to their superior properties, like weight to strength ratio. It mainly consists of Polymer as a matrix and fibers as a primary reinforcing material having a

distinct interface between them. The Fibers are of high strength and modulus mainly intended to bear the load which has being transformed by matrix.

Types of Reinforcement
1. Carbon Fiber
2. Glass Fiber
3. Aramid Fiber
4. Boron Fiber

\section{OBJECTIVES}

1. To develop new class of composites by incorporating the E-glass fiber and as primary reinforcing phases into polymer matrix composite.

2. To evaluate the mechanical properties there by investigate the strength of the fiber composite.

\section{PROPOSED WORK}

\section{A. Materials}

The proposed work, composite matrix is arranged by grouping of two materials. The following steps were followed to obtain the composite matrix.

1. Building of material matrix

2. Reinforcement of fiber

\section{Matrix Material (MM)}

Methyl ethyl ketone peroxides (MEKP) catalyst, Unsaturated Isophthalic Polyester (IPP) (VBR-4503) Resin matrix material, and Cobalt Naphthenate.

Table. 1. Typical Properties of Unsaturated Polyester Resins

\begin{tabular}{|c|c|}
\hline Physico-Mechanical properties & Value \\
\hline Grade & VB-4503 \\
\hline Density $\left[\mathrm{Kg} / \mathrm{m}^{3}\right]$ & $1100-1200$ \\
\hline Viscosity & $500-600 \mathrm{cps}$ \\
\hline Tensile strength [MPa] & $65-80$ \\
\hline
\end{tabular}

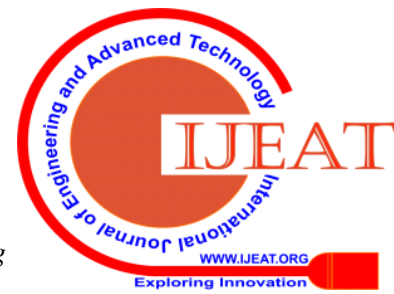




\begin{tabular}{|c|c|}
\hline Flexural Strength [MPa] & 108 \\
\hline Gel Time & $15-25$ mins. \\
\hline
\end{tabular}

\section{Reinforcement}

Bi-directional E-Glass fabric consist $\left( \pm 45^{\circ}\right)$ fiber orientation was used as a primary reinforcing having an aerial density of $380 \mathrm{gm}^{-2}$.

Table. 3.2. Typical Properties of E-Glass Fiber

\begin{tabular}{|c|c|}
\hline Physico-Mechanical Property & Value \\
\hline Tensile strength (MPa) & $1500-2200$ \\
\hline Elastic modulus (Gpa ) & $120-145$ \\
\hline Elongation at break (\%) & $0.2-0.9$ \\
\hline Specific gravity & 2.61 \\
\hline Melting temperature $\left({ }^{\circ} \mathrm{C}\right.$ ) & 2750 \\
\hline
\end{tabular}

\section{B. METHOD OF FABRICATION:}

Pre-calculated amount of polyester resin is mixed with 1.5 $\%$ MEKP catalyst as prescribed by vendors. SiC powder was dried in a muffle furnace at $150^{\circ} \mathrm{C}$ for about $1 \mathrm{hr}$ before mixing it with the resin. Cobalt Naphthenate (1.5 \%) accelerator is added to start the curing prior to reinforcement. Polyester/Glass fabric composites were prepared. Resin mixture impregnated E-glass fabric layer 220×220 mm were laid down on the surface of the mold one above the other until desired thickness is achieved. Silicon hard roller and brush facilitates degassing and ensures the uniform distribution of the resin. Each fabricated laminates were cured under pressure of 35 bar using hydraulic press for 24 hrs. Further laminates are removed from the mold and cured for $48 \mathrm{hr}$ at room temperature before use of the composites. All laminates for the mechanical tests were prepared from the eight layer of the E-glass fabric except the hardness test for which 16 layers of fabric were used. All laminates of the hybrid composites were processed at a weight fraction of $60 \%( \pm 1.5)$. Thickness of Laminates maintained uniform thickness of $3.2 \mathrm{~mm}$ using a spacer. Laminates for hardness test were made to $6 \mathrm{~mm}$ thickness.

\section{SPECIMEN PREPARATION}

Initially, the composites which are prepared for experimentation, the dimensions were marked and which use water processing. The specimens were prepared according to ASTM standards. The specimens were designed The test specimen along with specimen dimension and standards for different tests are discussed below.

\section{Density:}

Density of composites was measured using NETTLER-M tester by displacement method, according to ASTM D792, using electronic balance with an accuracy of $\pm 1 \times 10^{-4} \mathrm{~g} / \mathrm{cc}$.

\section{Hardness Test}

Hardness of samples with specific dimension $25.5 \times 25 \times 6$ $\mathrm{mm}$ is determined by SAROJ hardness tester following ASTM D785. During the test Carbide ball indenter with a spherical ball of $1 \mathrm{~mm}$ diameter is penetrated in to the surface of the composite matrix with the applied load of $150 \mathrm{~kg}$. Rockwell hardness was determined at different places for each composition. The average value will yield Rockwell hardness m-scale [HRm] for the specific composites.

\section{Tensile Strength}

Investigate the tensile behavior of fabricated composites by using Universal Testing Machine (UTM) LLOYD EZ 20. Tensile test is carried out in the specimen by placing the specimen in the jaw and axial load is applied till the specimen fractures. Tensile load is recorded corresponding to the deflection in the gauge length. Different compositions of unfilled and SiC Filled G-P composites were prepared according to ASTM D638 of dimension $165 \times 20 \times 3.2 \mathrm{~mm}$ (DUMBBELL SHAPE) as shown in Fig. 1. During which UTM is performed at a speed of $5 \mathrm{~mm} / \mathrm{min}$ at an Ambient Temperature (AT) conditions and humidity conditions

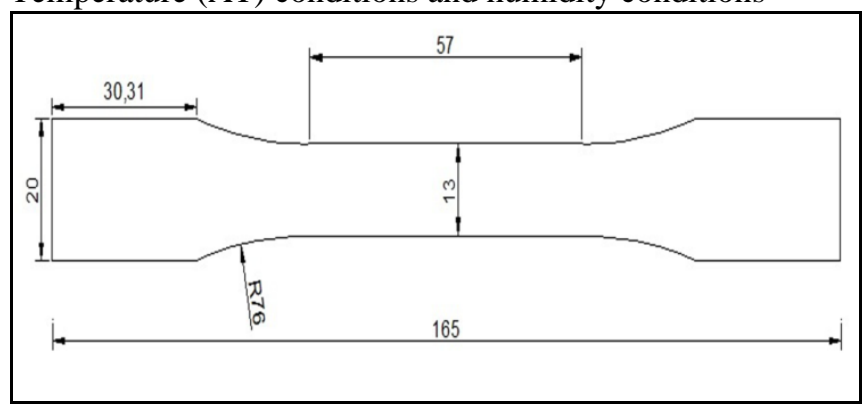

Fig. 1. ASTM D638 dimension of Tensile Specimen.

\section{Flexural Strength}

Bending behavior of fabricated composites under three point bending configuration is determined using UTM LLOYD EZ 20. Insertion the specimen of selected dimension on the machine and applying force until it fractures and breaks involved in testing process. Present investigation samples of unfilled G-P composites for flexural tests were made in accordance to ASTM D790 of dimensions 127 $\times 12.7 \times 3.2$ as shown in the Fig.2. During which UTM is operated at speed of $2 \mathrm{~mm} / \mathrm{min}$ at an AT and humidity conditions.

Flexural strength is calculated by the following equation $\sigma=\frac{3 F L}{2 b d^{2}}$

$\sigma$ is the outer fiber stress at mid point (MPa).

$F$ is the load (force) at the fracture point (N)

$L$ is the length of the support span (mm)

$\mathrm{b}$ is width (mm)

$d$ is thickness (mm)

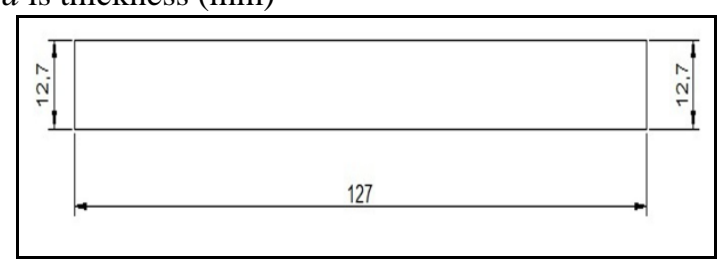

Fig. 2. ASTM D790 dimension of Flexural (Three point bend test) Specimen

Nafissa Gull [3] discusses the effect of $\mathrm{ZnO}$ on Glass Fiber Reinforced (GRF) polyester composites. They found that a mechanical property and thermal property of GRF polyester composites improves with addition of $\mathrm{ZnO}$ filler content.

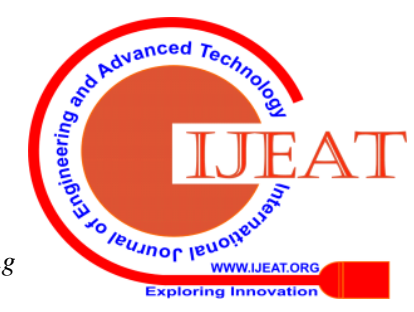


Flexural modulus and strength are developing by quantity of filler content up to $3.0 \mathrm{wt} \%$ of $\mathrm{ZnO}$ and then it is decreased. Hardness and impact strength progressively increases with increase in filler content.

An experimental study on multilayered laminates from glass fabric/graphite/epoxy composites properties of mechanical and sliding wear carried out by Shivamurthy[4].

They concluded that by adding graphite fillers to glass fabric / graphite / epoxy composites which leads to its improvement in mechanical properties.

The mechanical properties which mainly contribute to fiber matrix composites are flexural strength, Young modulus, tensile power and impact force. $3 \mathrm{wt} \%$ of graphite filled with the composites and it exhibits lower wearer rate and best mechanical performance.

Julio Cesar et al. [5] discussed the influence of silicon carbide addition in to the fiber glass reinforced composites. They conclude that micron silicon carbide particle increase apparent density, flexural strength but flexural modulus was not significantly modified.

Spherical shaped filler fly ash improved the mechanical properties by incorporating in to the polypropylene composites as reported by Jitendra et al. [6]. They further clearly stated that smaller particles yields better improvement than larger particles.

\section{RESULT AND DISCUSSION}

The test analysis and the mechanical behavior of composites is one of the most important stages of the investigation. Mechanical properties of fiber and FRC depend on the following factors as matrix material nature, orientation of the fiber, the distribution and reinforcing of fibers, the interface between the reinforcement and the fiber-matrix. It is also observed that even small change in the physical nature or the properties mentioned above of the reinforcement will have an impact in the experimental results.

The experimental results are analysed and discussed to identify the mechanical behaviour in the following ways

1. Density of composites

2. Hardness of composites

3. Tensile strength of composites

4. Flexural strength of composites

\section{Physico-Mechanical Properties of the Composites}

Tensile test and flexural test are carried out by using UTM machine, and Rockwell hardness test machine for determine the hardness value. Specific gravity of the materials is determined using density tester. The composite specimens are prepared based on the ASTM standards according to each test.

\section{Density}

Density of the tested specimen has found to be $1.18 \mathrm{~g} / \mathrm{cc}$.

\section{Hardness}

When compression stress is put on the composites, matrix, fiber and filler are subjected to external pressure, the resistance to deformation or penetration or increase in the hardness, when compression stress is applied on the composites, matrix, fiber and filler are subjected to external pressure. This pressure facilitates the primary and secondary reinforcements to contact extensively. Therefore interface transfers load is highly effective though interfacial bond may be weak. Other factors also influence the hardness factor. Increase in adhesion between matrix polyester and reinforcement. $89 \mathrm{HRm}$ value was found on the unfilled G-P Composites.

\section{Tensile Test}

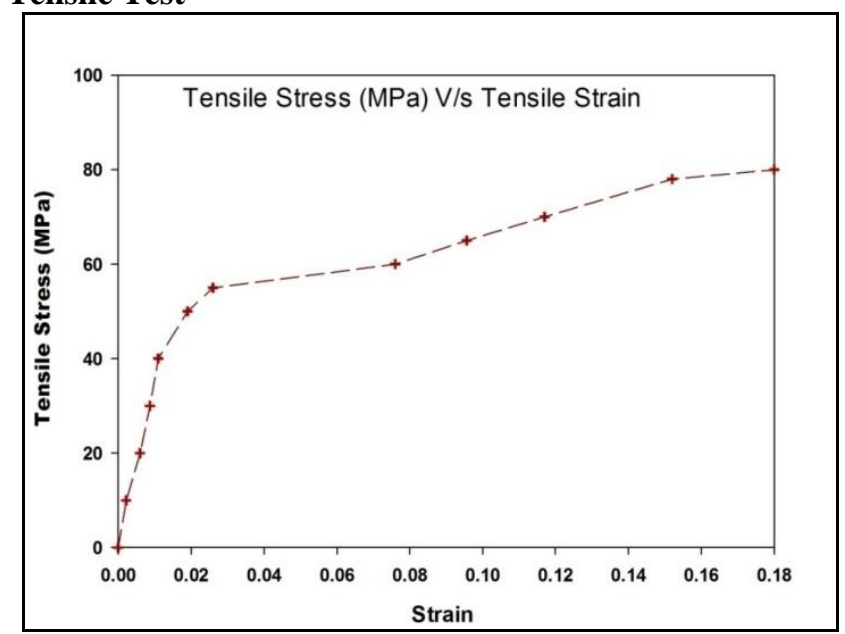

Fig. 3. Tensile stress-strain curve for G-P composite.

The different compositions of the composite models are tested in UTM and samples are left to break till it attains the absolute strength. Tensile stress-tensile strain curve plotted to determine the young's modulus and strength. Stress-strain curve for the different composition of the composites is shown in the Fig. 3. From the Fig. 3, it is seen that Stress-strain curve is found linear from 0.01 to $0.05 \%$ strain. Maximum deflection of $18 \mathrm{~mm}$ obtained at $3000 \mathrm{~N}$ for unfilled G-P composites.

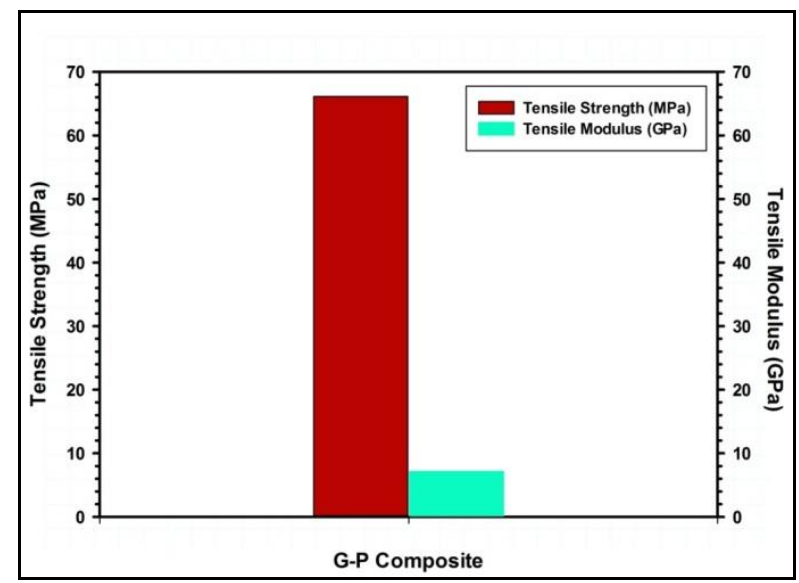

Fig. 4. Tensile strength and tensile modulus of the G-P composites.

Tensile Strength and Modulus of G-P composites are as shown in the Fig. 4. $68 \mathrm{MPa}$ is the tensile strength of the glass polyester and $7.8 \mathrm{GPa}$ is the modulus of the glass polyester composites respectively. Flexural stress strain curve G-P composites is shown in Fig 5. 


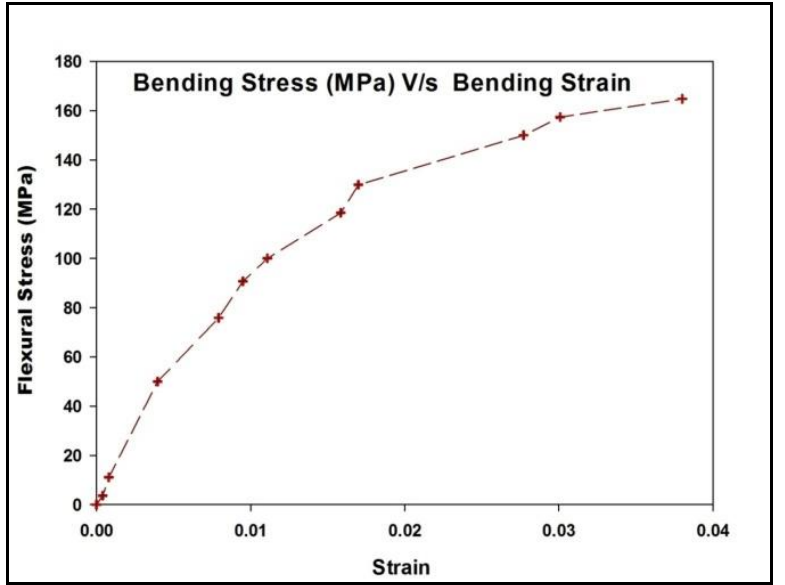

Fig. 5. Flexural stress strain curve of G-P composites.

\section{CONCLUSION}

This part of the report includes the conclusions drawn out of results obtained from the experimentation and the scope to continue the work further.

1. The Unfilled Glass fibre reinforced polyester (GPR) composites are synthesized and characterized successfully.

2. As per the ASTM standards condition the density, hardness, tensile strength and flexural strengths are determined.

\section{REFERENCE}

1. S. Chauhan, Anoop Kumar and Amar Patnaik, "Mechanical and wear characterization of GF reinforced vinytl ester resin composites with different monomers," J. Reinf. Plast. Compos. 2008.

2. U. Nirmal, K. O. Low, J. Hashim, "On the effect of abrasiveness to process equipments using Betelnet and glass fiber reinforced polyester composites,"Wear. vol. 290-291, pp. 32-40, 2012.

3. G. Nafisa, M. K. Shahzad, A. M. Muhammad, S. Muhammad, A. Farheen, T. Z. B. Muhammad, J. Tahir, "Synthesis and Chracterization of zinc oxide $(\mathrm{ZnO})$ filled glass fiber reinforced polyester composites," Mater. Des. vol. 67. pp. 313-317, 2015.

4. B. Shivamurthy, K. Udaya Bhat, S. Anandhan, "Mechanical and sliding wear Properties of multilayered laminates from glass fabric/graphite /epoxy composites," Mater. Des. vol. 40. pp. 136-143, 2013.

5. C. D. S. Julia, B. T. Rubens, M. G. V. Luciano, M. V. M. Zlia, L. C. Andre, H. P. Tulio, "The effect of silicon carbide addition into fiber glass reinforced composites, “Int. J. Compos. Mater. vol. 15. pp. 92-96. 2012.

6. G. Jitendra, G. K. Vijay, R. Gunti, "Evaluation of flexural properties of fly ash filled polypropylene composites," Int. J. Modern Research [IJMER] vol. 4. pp. 2584-2590, 2012.

\section{AUTHORS PROFILE}

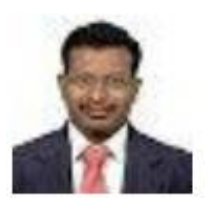

R.Praveen, Asst. Professor Department of Mechanical Engineering, Aarupadai Veedu Institute of Technology Vinayaka Mission Research Foundation, Deemed To Be University. praveen@avit.ac.in

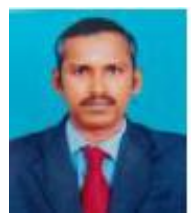

P.Kumaran, Asst. Professor Department of Mechanical Engineering, Aarupadai Veedu Institute of Technology, Vinayaka Mission's Research Foundation, Deemed To Be University. kumaranp@avit.ac.in

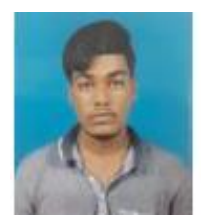

Akash - UG Scholar, Department of Mechanical Engineering Aarupadai, Veedu Institute of Technology, Vinayaka Mission's Research Foundation, Deemed To Be University

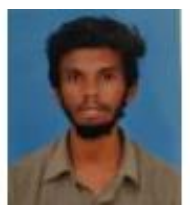

Divya Krishna, UG Scholar, Department of Mechanical Engineering, Aarupadai Veedu Institute of Technology, Vinayaka Mission's Research Foundation, Deemed To Be University

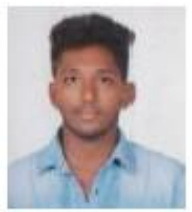

Kavin kumar, UG Scholar, Department of Mechanical Engineering, Aarupadai Veedu Institute of Technology, Vinayaka Mission's Research Foundation, Deemed To Be University. 